JOURNAL OF APPLIED CRYSTALLOGRAPHY

ISSN 1600-5767

\section{Broader Impacts of Science on Society. By Bruce J. MacFadden. Cambridge University Press, 2019. Pp. 320. Price GBP 19.99 (paperback). ISBN 9781108434287.}

\author{
John R. Helliwell*
}

Department of Chemistry, University of Manchester, Manchester M13 9PL, UK. *Correspondence e-mail: john.helliwell@manchester.ac.uk

This book by Bruce J. MacFadenn, a palaeontologist, is linked to the Broader Impacts Program of the US National Science Foundation (NSF), which he became aware of whilst he was a professor and faculty curator at the Florida Museum of Natural History. Clearly enthusiastic about broader impacts, he taught a graduate seminar course on the subject for seven semesters. He writes in his Preface 'I thank my students in these classes for their enthusiasm. Unlike some of my more senior colleagues, who are set in their ways, the next generation 'gets' NSF's Broader Impacts and related activities that benefit society.' In the UK our research councils faced a similar negative reaction, even backlash, to research impact statements in grant proposals. This is a serious culture clash seen by many scientists as an attack by the funding agencies on curiosity-driven research, naturally cherished by us scientists. I did not worry about this and was glad to see the impact of my work as a protein crystallography beamline scientist at the UK's Synchrotron Radiation Source (SRS) in analytical services for industry. As an enthusiastic member of our SRS annual report committee, I always regarded the benefits to industry and society narratives as golden nuggets. So, I see this as an important book from an experienced enthusiast in the parallel culture to the UK of the USA. Furthermore, the author worked for two years as an NSF program officer and represented NSF at the American Association for the Advancement of Science (AAAS), presenting talks on broader impacts.

Chapter 1 is entitled Introduction: Science, STEM [Science, Technology, Engineering, and Math], and Society and offers a core idea that 'there has been tension between 'ivory tower' science and government oversight and accountability. The extent to which society values basic research is at the core of the debate about return on investment of government funds.' This seemingly correct statement conceals the truth that government is a proxy for the voters, i.e. taxpayers. Do governments really know in detail what taxpayers want from science and scientists? Maybe it is best in these days of 'fake news protagonists' in politics that an organization such as the non-partisan Pew Research Center (https://en.m.wikipedia.org/wiki/Pew_Research_Center) does the documenting of the data on the variations of opinions of the US public and US scientists (Fig. 1.6), showing big opinion gaps on topics such as GM food safety, climate change and evolution. MacFadden is incisive with his section on diversity, highlighting the poor representation of women and minorities in the USA and elsewhere, as well as the mismatch of supply of PhDs to jobs within different STEM sectors (except in computer sciences), and he shows explicitly how 'we will not have fulfilled our social responsibility or realized the economic benefits of diverse participation in STEM'.

Chapter 2, entitled NSF and Broader Impacts, provides a clear historical description of NSF's foundation and development. Fig. 2.1 shows the first page of the US NSF Foundation Act of 1950, and its first sentence sets the scene for all that follows, including in effect broader impacts: 'To promote the progress of science; to advance the national health, prosperity and welfare; to secure the national defence; and for other purposes.' Annual review and oversight of NSF by both Senate and House of Representatives science committees commenced in the 1960s. The chapter also has interesting descriptions of particular US senators who highlighted what on the face of it, from their research grant titles, looked like 'silly use' of tax payers' money. These led to demands to know the referees who had supported such silly sounding research, which information NSF refused to release, instead redacting such details. 
Chapter 3 is on Innovation, Opportunity, and Integration. It highlights several case studies, including of the author's work in Panama excavating 20-million-year-old fossil mammals. The chapter wrestles with NSF policies for taking risks in encouraging adventurous research but not too much risk, thereby potentially jeopardizing ROI (return on investment of the taxpayer funds they shepherd). A subtext is apparent, that the riskier projects are at the small-budget end of things. This chapter, like those before it, is a very solid treatment of important topics. Box 3.1 entitled $3 D$ Megalodon, Integration, and STEAM (STEM including arts) is a delightful mosaic of five photos showing teachers and students clearly happy to be taking part in a project about a 10-million-year-old giant shark, Carcharocles megalodon, and its tooth from Panama. This study was also chosen by the author to illustrate how a researcher can tap into undersubscribed funding schemes.

Chapter 4 is on Communication and Dissemination. There are real gems in this chapter, showing the depth of the author's experience both as a scientist presenting to specialist audiences at all levels and as a speaker to the public on his science. For yet further added value he was for two years in charge of NSF's 'Communicating Research to Public Audiences' (CRPA) program. Tellingly, the CRPA program was 'never very popular in terms of number of proposals submitted. It ultimately ended.' The question then is why training in this skill was not made mandatory by NSF as a condition of a research grant, i.e. was a 'proposals route' the correct administrative instrument for optimizing broader impacts (to use a European term)? Box 4.1 is one of the gems, covering the presenting of a similar talk to different audiences.

Chapter 5, Promoting Yourself and Optimizing Impact, is a broad-brush solid survey of publishing, including open access, metrics uses and abuses, and social media. In my own book Skills for a Scientific Life (Helliwell, 2017) I covered the same topics but with a greater emphasis on formal press releases and the media. I also stressed the need to avoid negative impacts, such as premature press releases or premature appearances on radio and television. This latter point is especially important I think, as it can do science in general harm if the public's time is wasted on such as 'in five years' time we may see a new medicine or cure' etc. etc. Box 5.1 does provide helpful Novice's Tips on Press Releases.

Chapter 6 describes Collaboration, Authorship, and Networks. This chapter has highs and lows in its descriptions of these topics. The author's experiences at NSF bring in nice descriptions of several initiatives that advanced broader impacts, set in the context of examples of the author's 50 years in scientific research. The section on professional networking such as LinkedIn carries with it the somewhat disappointing caveat 'Although I do not use many of these tools myself, I do understand the benefits.' He also does not describe Kudos, favoured by some publishers I know for explaining one's research articles in simpler language for a wider audience because of its broader impacts. Box 6.2 highlights the USA's 'National Alliance for Broader Impacts', which strikes me as excellent.
Chapter 7 is Strategic versus Curiosity Science. This again is a well thought out chapter. It is very US NSF focused though, but neatly connects to earlier chapters. It introduced to me the term 'charismatic science': if you are going to undertake a curiosity-driven topic, rather than be in a strategic (NSF) research theme, then try and select something with likely popular appeal (it will expedite one's broader impacts efforts later). NSF's future Big Ideas listed on page 92 are an interesting glimpse of US thinking.

Chapter 8 is entitled Know Your Audience and is again a solid chapter with numerous gems. Not only is there the author's academic outreach work and his NSF Officer background, providing diverse and very good experience that he shares with us, but his role as Museum Director adds dimensions unfamiliar to many of us. The sections in this chapter cover formal, informal, multicultural and international audiences as well as online, blended and social media audiences. He depicts trends over the decades since 1939 of visitors to the Florida Museum of Natural History in Fig. 8.4, and in Fig. 8.5 shows an analysis of the Museum's engagements via social media in late 2018. Both figures show audiences into the hundreds of thousands. The paragraph on page 103 about the need for US Institutional Review Board approval for collecting demographic data could be vital in specific cases, and a reference to how the University of Florida does it is given.

Chapter 9 is on Diversity, Equity, and Inclusion. This a very heterogeneous coverage of topics ranging from the situation of women in STEM (including underrepresentation, unfair pay and harassment policies), disabilities and avoiding barriers for the disabled, outreach to the prisoner population (2.2 million in the USA, including 60000 juveniles), and underrepresented minorities in general. The chapter is good and interesting but with the obvious danger of insufficient detail. There are various references given, however, for further reading. For the International Year of Crystallography, I approached the UK's Prisoners' Education Trust (PET), offering a broadly based lecture on crystallography and the molecules of life, having first obtained the support of the IUCr and the BCA, albeit preliminary at that stage. PET said they would mention my offer in their newsletter, but there were no takers, and they explained to me that practical skills training, e.g. as chefs or car mechanics, was preferred. The USA seems to have the broader programme I had in mind.

Chapter 10 is on Mentoring and Role Models. The terminology, as I have remarked before (Helliwell, 2017, ch. 24, p. 108), is different in the UK and the USA. In the UK we distinguish carefully between the roles supervisor, advisor and mentor. In this book, for example on page 127 on the attributes of quality mentoring, the key item of 'critical friend' is missing from the list. Also, no mention that, in the workplace, a mentor and mentee should meet in a place different from either person's department or workplace. No mention either of the need for strict confidentiality. Outreach lectures and visits to schools are, to me oddly, referred to as 'outreach mentoring'. The other chapters are excellent on definition setting but I think fail here. In the UK scientific civil service, 
additional terms and roles would be line manager and senior line manager. The chapter includes helping the early-career researcher secure their permanent position, but the author does not include mentoring of those later-career scientists at a career ceiling. So, this is a less good chapter in its descriptions, I think.

Chapter 11 is on Formal K-12 Education and Partners. The author describes the K-12 environment, expectations and realities, teacher professional development, NSF's scheme for research experience for teachers, and best practices and resources. He reflects that the overproduction of $\mathrm{PhDs}$ could have been turned by NSF towards helping those school districts that cannot effectively recruit and retain qualified science teachers. Specifically, 'It is unfortunate that this career pathway is not more firmly embraced by scientists and K-12 educators; it potentially would transform US workforce development and K-16 education in the twenty-first century.' A very positive remark is also offered by his quotation at the start of his Concluding Comments of this chapter of a New York teacher, that 'the single most important thing that practising scientists in any field can do is reach out to teachers and students at a local high school'.

Chapter 12 is on Higher Education. The section on massive open online courses (MOOCs) captures efforts in both the USA and other countries; there are 9400 MOOCs offered by 800 universities which reach 78 million students. There are sections on US community colleges and on the teaching of broader impacts to graduate students (with a nice syllabus in Inset 12.1), and a description of undergraduate summer internships.

Chapter 13 is Informal STEM Learning in Museums and Beyond. This chapter is in the author's core strengths and the reader is again richly rewarded by his deep and wide experiences with exhibits, especially obviously fossils, be it dinosaurs in Chicago O'Hare airport or on a mobile bus, or festivals featuring fossil elephants. The joyful expressions of the youngsters pictured are eloquent testimony to the success of these efforts. The mass media section (TV etc.) could have mentioned the huge broad global impact of the climate change protests and the media interest in the 'trust the science' headline achieved by Extinction Rebellion and the Friday school climate change protests.

Chapter 14 is entitled Public Participation and Community (Citizen) Science. It clearly distinguishes different types of participant, such as the cohort of retired scientists and the, basically untrained, enthusiasts. This leads on to discussing pitfalls and cautions with using community science data. The overall tone is enthusiastic and that it is 'a big deal with immense potential for strategic impacts'. Example projects include e.g. fossils, ornithology, and studies of ants and oysters.

Chapter 15 is on Computers and Cyberimpacts. This is a wide-ranging chapter and thereby to a degree lacking depth. It spans cyberlearning, learning and social networks, mobile phone apps, virtual and augmented reality, and NSF's Grand Challenge of 'Big Data'. Fig. 15.7 is a pie chart showing that for the Florida Museum of Natural History social media is $68 \%$ of the activity and their web site $26 \%$, i.e. taken together these two are $94 \%$. (Here, with the word 'activity', the author is referring to that from 'cybervisitors' as distinct from actual museum visitors.) That said he emphasizes that 'reach isn't a measure of impact which needs assessment and evaluation'.

Chapter 16 is on Developing a Broader Impacts Plan, and the author shares his great experience on this, both NSF specific and also quite general advice. Chapter 17 is on Project Management and Sustainability. This is quite similar in style to chapter 16, being rather NSF specific. It is packed with helpful advice to grant applicants. Chapter 18 is entitled Were you successful? Evaluation and Metrics, and as one would expect from the title is more general. Adopting SMART goals (specific, measurable, assignable, realistic and time related) makes evaluations more effective.

Chapter 19 is on Wrap-Up, the Future, and Broader Impacts 3.0. Fig. 19.1 is a word cloud of the 30 most frequently used words in the book. The top five are science, NSF, broader impacts and STEM. Also listed are the dominant themes (Inset 19.1). The chapter nicely emphasizes the social responsibilities of scientists via effective execution of broader impacts alongside making important discoveries.

Near the start of the book there are 89 listed Abbreviations, Definitions, and Acronyms. Besides NSF, NIH, PI etc. we see listed interesting terms such as DCL (dear colleague letter, NSF) and NOS (nature of science). There are 30 pages of references, with titles and an extensive subject index. The book is well written and nicely illustrated with a wide variety of figures and boxed texts for emphasis.

Overall this is an impressive book with great depth and breadth. The NSF emphasis will be of great value to those based in the USA and certainly I think of interest to the wider community of scientists, teachers and the science media at large around the world.

\section{References}

Helliwell, J. R. (2017). Skills for a Scientific Life. Boca Raton: CRC Press/Taylor and Francis. 